\title{
Tinjauan Model Penta Helix pada Ketahanan Pangan: Lumbung Padi Kabupaten Lingga
}

\author{
Ardi Putra ${ }^{1}$; Laxy Dwi Asmara ${ }^{2}$; Mahadiansar Mahadiansar ${ }^{3}$; Aspariyana \\ Aspariyana $^{4}$ \\ 1,2 Program Studi Ilmu Pemerintahan, Fakultas Ilmu Sosial dan Ilmu Politik \\ Universitas Maritim Raja Ali Haji, ardiputra@umrah.ac.id, \\ laxydwiasmara98@gmail.com \\ ${ }^{3}$ Program Studi Pascasarjana Ilmu Kebijakan Publik, Fakultas Ilmu Administrasi \\ Universitas Brawijaya, mahadiansar@student.ub.ac.id \\ ${ }^{4}$ Program Studi Sosiologi, Fakultas Ilmu Sosial dan Ilmu Politik \\ Universitas Maritim Raja Ali Haji, riyanaaspa@gmail.com
}

\begin{abstract}
Abstrak
Tulisan ini menjelaskan kondisi ketahanan pangan di daerah kepulauan pada masa pandemi COVID 19 di Provinsi Kepulauan Riau salah satunya Kabupaten Lingga. Peneliti mengunakan model penta helix untuk menganalisis sejauh mana keterlibatan para aktor dalam pengembangan sektor ketahanan pangan khususnya pada program Lumbung Padi. Adapun metode penelitian digunakan ialah kualitatif deskriptif yang kemudian di analisis secara mendalam dengan mengunakan data sekunder yang ada. Hasil menunjukan bahwa analisis menggunakan model penta helix yang terdiri dari lima unsur yaitu pemerintah sebagai pembuat kebijakan, kerjasama industri, keterlibatan kelompok masyarakat, kajian dari perguruan tinggi serta media sebagai informasi dan publikasi pada ketahanan pangan yang sangat memiliki peran yang saling berkaitan pada sektor ketahanan pangan khususnya pada program lumbung padi di Kabupaten Lingga, namun perlu diperhatikan bahwasanya keterlibatan pemangku kepentingan harus memperhatikan aturan serta regulasi dalam upaya menjaga stabilitas ketahanan pangan pada lumbung padi dari segi kualitas dan kuantitas produksinya ditengah pandemi COVID-19.
\end{abstract}

Kata kunci : Ketahanan Pangan, Lumbung Padi, Kabupaten Lingga, Penta Helix,

\begin{abstract}
This paper explains the condition of food security in the archipelago during the COVID 19 pandemic in the Riau Islands Province, one of which is the Lingga Regency. Researchers use the Penta helix model to analyze the extent to which actors are involved in the development of the food security sector, especially in the Rice Granary program. The research method used is descriptive qualitative which is then analyzed in-depth using existing secondary data. The results show that the analysis uses the Penta Helic model which consists of five elements, namely the government as a policymaker, industrial cooperation, community group involvement, studies from universities and the media as information and publications on food security which have a very interrelated role in the food security sector especially in the rice barn program in Lingga Regency, however, it should be noted that the involvement of stakeholders must pay attention to rules and regulations in an effort to maintain food security stability in rice barns in terms of quality and quantity of production amid the COVID-19 pandemic.
\end{abstract}

Keywords : Food Security, Penta Helix, Rice Granary, Lingga Regency. 


\section{Pendahuluan}

Sektor ketahanan pangan di Indonesia memiliki peran penting untuk meningkatkan kesejahteraan dan perekonomian masyarakat berkembang hal ini dikarenakan akan menurunkan kesenjangan kemiskinan di Indonesia. Nyatanya bukan hanya di indonesia saja, akan tetapi dibeberapa negara berkembang yang memiliki potensi ancaman yang mengarah kepada kegagalan sehingga sangat rentan kerawanan pada pasokan pangan yang pastinya nanti berdampak pada perkonomian diberbagai sektor yang ada (Adjognon et al., 2021; Udmale et al., 2020). Sejak awal terjadinya penyebaran virus pandemi COVID-19 masuk di Indonesia (Setiawan \& Mahadiansar, 2020; Shuttleworth, 2009), PDB pada Sektor pangan mengalami pertumbuhan domestik bruto (PDB) pada level kuartal kedua dan ketiga tahun 2020 masing-masing menjadi minus 5,32\% dan menurun kembali menjadi minus $3,49 \%$.

Pastinya bukan hanya sekedar ancaman sebuah resesi, pandemi COVID19 juga berpotensi akan mengancam terjadinya krisis pangan yang berkepanjangan seperti yang telah diwaspadai oleh organisasi internasional yaitu Badan Pangan Dunia (Yuliawati, 2020). Pangan anugerah yang dimiliki makhluk hidup yang asal usulnya dari ragam hayati seperti produk perkebunan, pertanian, perairan yang diperoleh dan mampun diolah secara langsung maupun tidak langsung. Kemudian untuk kegunaannya pasti akan bermanfaat pada sebuah produk berupa munuman dan makanan yang layak dikonsumsi oleh manusia. Hal ini membuat akan di campur dengan tambahan bahan baku dengan yang lainnya agar bisa dilakukan proses pengolahan atau distribusi tambahan minuman dan makan.

Ketahanan pangan akan berpengaruh pada tingkat pangan pada level mikro dan makro sehingga ketika kebijakan yang akan dibuat tidak tepat sasaran dan bisa menyebabkan konflik sesama warga negara. Hal ini perlunya sebuah upaya berupa tantang untuk penguatan sektor kelembagaan baik dari sisi pemerintah daerah baik secara formal maupun informal dengan melihat kondisi lingkungan yang ada (Blekking et al., 2020; Brück \& d'Errico, 2019; Shields \& Stojetz, 2019). Selain itu ketahanan pangan merupakan sebagai bentuk dari perlindungan sosial yang berfokus pada kehidupan manusia di dunia. Ini terlihat jika sebuah produk yang 
telah dihasilkan mulai dari sis bentuk kualitas pangan dan sumber kebutuhan lainnya pada sebuah kerangka wilayah pada setiap generasi manusia itu sendiri (Doocy et al., 2019; Helton et al., 2018), namun faktor pengaruh lainnya dari sektor ketahanan pangan juga adalah upaya dari mitigasi atau perubahan iklim juga sangat penting untuk membatasi dampak merugikan dari perubahan iklim terhadap produksi ketahanan pangan (Doelman et al., 2019; Vannozzi Brito \& Borelli, 2020).

Pada kondisi saat ini, untuk menjawab sektor ketahanan pangan pada saat ini, perlunya keterlibatan dari semua pihak pemangku kepentingan atau aktor yang ada dengan memperkuat kerjasama agar segala kekurangan sektor ketahanan pangan bisa di atasi dengan baik di masa pandemi COVID-19 (Nechifor et al., 2021; Redjeki, 2020). Selanjutnya ada poin penting dalam mengatasi ketahanan pangan di negara berkembang termaksud di indonesia diantaranya yang pertama ketahanan pangan yang dimana sebuah wilayah mempunyai kewajiban untuk menjamin atau memprioritaskan ketersediaan ketahanan pangan baik dalam jumlah yang besar maupun jumlah yang memiliki target dari segi kualitas untuk setiap masyarakat dimana mereka memiliki hak, karena pada prinsipnya masyarakat mempunyai hak dan kewajiban yang sama.

Hal ini bertujuan untuk meningkatkan taraf keberlangsungan lingkungan yang baik. Kemudian dari pada itu ketersediaan akan pangan dalam sebuah wilayah bernegara harus memaksimalkan untuk melakukan optimalisasi dengan cara berkelanjutan agar dengan perkembangan zaman akan meningkat apalagi pada setiap tahunnya jumlah atau laju pertumbuhan penduduk di setiap negara (Dinda, 2020), kemudian yang kedua pangan berbasis kemandirian dimana dalam sebuah wilayah mampu melihat potensi akan kebutuhan masyarakat, karena di dalam suatu negara yang memiliki kekuasaan otonom atas hak dan wewenang pastinya tidak mengharapkan di wilayah lainnya dari berbagai sektor yang terkait dengan ketahanan pangan seperti ekonomi, sosial, budaya, agama dan yang lainnya.

Ketiga kemampuan pangan atau biasa disebut dengan aksesibilitas pada masyarakat terhadap dapur istri akan kebutuhan bahan pangan sangat menjamin keberlangsungan pada daya pasar di beberapa wilayah, nantinya daya terhadap pasar sangat mempengaruhi pendapatan asli daerah. Hal ini pasti akan mengarah 
pada sebuah spesifikasi produk komoditas sebuah ketahanan pangan. (Bairagi et al., 2020). Selanjutnya yang terakhir daya konsumsi pada pangan, kekuatan konsumsi akan pangan berhubungan dengan kualitas berupa gizi yang memadai serta ideal agar pangan yang diperoleh memiliki kuantitas serta kualitas yang baik pada gizi untuk keperluan masyarakat. Jika keperluan terpenuhi maka sangat berdampak pada perekonomian, kesejahteraan sosial serta kondisi adat dan budaya di wilayah tersebut (Walls et al., 2019).

Pada perbaikan ketahanan pangan sebagai bentuk salah satu strategi kebijakan demi memperkuat upaya pemekaran sistem pertanian dengan berbagai inovasi, inovasi yang dimaksud dimana ketahanan pangan telah di diimplementasikan secara terus menerus dan dievaluasi secara berkelanjutan dalam sistem pertanian belum dievaluasi secara sistematis (Nicholson et al., 2021). Konsep penta helix sebagai upaya inovasi pengembangan potensi ketahanan pangan demi membangkitkan ksejahteraan masyarakat agar sebuah wilayah bisa mandiri untuk mengelola kompleksitas problematik pada aktor yang terlibat dalam ketahanan pangan (Halibas et al., 2017; Yunas, 2019).

Penta helix juga merupakan solusi sebuah seluruh industri termasuk sektor ketahanan pangan secara berkelanjutan yang merupakan keterkaitan antara lima unsur yaitu pemerintah, lembaga pendidikan, lembaga penilaian lingkungan, masyarakat, dan industri ketahanan pangan yang saling berkoordinasi saling terintegrasi dengan baik (Amrial et al., 2017). Kolaborasi dalam Penta-Helix biasa disebut Academic, Business, Community, Government, and Media (ABCGM) menciptakan sistem ketahanan pangan yang kuat sehingga meningkatkan produksi pangan sebagai bagian dari ketersediaan pangan daerah dan nasional (Sumarniasih \& Antara, 2020).

Kabupaten Lingga sebuah kabupaten yang ada di provinsi Kepulauan Riau yang mempunyai potensi pada pemetaan potensi di sektor ketahanan pangan meskipun pada dulunya daerah kepulauan tersebut hanya fokus pada sektor kelauat dan perikanan, kini Kabupaten Lingga berfokus pada recovery ekonomi di masa pandemi COVID-19 dengan memperkuat program-program yang memiliki potensi, salah satu program Kabupaten Lingga dalam membangun daerahnya dari 3 sektor, 
yang pertama sektor pariwisata dengan konsep pemberdayaan masyarakat (Mahadiansar \& Aspariyana, 2020; Pratiwi et al., 2019), sektor kelautan dan perikanan sebagai daerah kepulauan (Yudiatmaja et al., 2020), sektor kehutanan serta sektor pertanian yang melibatkan semua aktor kepentingan. Sektor ketahanan pangan berbagai macam aktivitasnya diantaranya seperti sawah, ladang, ternak serta perkebunan (Adiguna \& Asyiawati, 2019).

Berdasarkan penelitian terdahulu, dibukanya lahan pertanian ini untuk menyejahterakan masyarakat dan membuka peluang kerja bagi masyarakat Kabupaten Lingga (Pursyahdad, 2018), akan tetapi keterlibatan terhadap unsur pemangku kepentingan tidak dijelaskan secara jelas. Pemangku kepentingan yang dimaksud adalah keterlibatan perguruan tinggi, media serta komunitas petani dalam mengambil peran penting pada pengembangan ketahanan pangan pada program ketahanan pangan lumbung padi di Kabupaten Lingga, ini dikarenakan pentingnya keterlibatan semua aktor agar terlihat sebuah kebijakan bisa diperbaiki.

Demi mewujudkan pada titik keberhasilan dari sebuah program ini yang menjadi pertimbangan besar bagi daerah yaitu pada peran dari masyarakat yang diberdayakan oleh pemerintah itu sendiri. Dari program Pertanian tersebut yang sangat terlihat menonjol adalah dari sektor perkebunan atau persawahan lumbung padi. Pemerintah Daerah Kabupaten Lingga memang sangat memfokuskan berupa pembangunan dari sisi persawahan dan perkebunan untuk membangun wilayah Kabupaten Lingga sebagai lumbung padi untuk mewujudkan visi dan misi kepala daerah.

Lahirnya proses pembukaan penguatan sektor ketahanan pangan berdasarkan perubahan rencana strategis (RENSTRA) 2016-2021 sesuai dengan VISI dan MISI Kepala Daerah Bupati Lingga yang diwakili oleh Dinas Pertanian dan Ketahanan Pangan Kabupaten Lingga. Salah satu point terpeningnya adalah dengan adanya pembukaan lahan pertanian secara berkala dimana Kabupaten Lingga memiliki proses lahirnya penguatan terhadap ketahanan pangan untuk menjadi ketahanan pangan nasional. Pada saat ini Pemerintah Kabupaten Lingga dalam masa pandemi COVID-19 menargetkan kembali program ketahanan pangan dengan membuka lahan sebesar 3000 hektar lokasi lumbung padi. Hal ini menjadi 
fokus utama agar ketergantungan cadangan pangan bisa mandiri dan tidak bergantung dengan pasokan pangan di wilayah lain, pengiriman akan cadangan pada pangan bisa menipis jika daerah kepulauan tersebut pada saat ombak laut tinggi sehingga pengiriman tersebut bisa terhambat, untuk mengunjungi kabupaten lingga saja hanya dengan transportasi laut yang rutin berlayar antar wilayah setiap harinya.

Namun pada masa pandemi COVID-19, Kabupaten Lingga sudah bisa menghasilkan bahan pangan sendiri. Bahkan, sudah bisa memasok 32,4 persen kebutuhan beras Lingga per bulan. Tujuan dari tulisan ini untuk menganalisa menggunakan model penta helix pada Ketahanan Pangan di sektor pertanian khususnya Lumbung Padi di Kabupaten Lingga yang dimana aktor kepentingan mulai dari kajian akademisi, pemberdayaan komunitas pertanian, peran pemerintah daerah serta keterlibatan media dan industri ketahanan pangan pada masa pandemi COVID-19.

\section{Metode}

Adapun lokasi penelitian dilakukan di Kabupaten Lingga pada tahun 2020, metode penelitian bersifat kualitatif yang dimana kualitatif tersebut melihat fenomena yang nyata terjadi didalam kehidupan sehari-hari (Creswell, 2014; Moleong, 2012). Batasan pada penelitian ini secara terwakilan pada objek dengan mengunakan analisis penta helix yang terdiri dari beberapa indikator yaitu melibatkan pemerintah sebagai pencetus program ketahanan pangan pada lumbung padi Kabupaten Lingga, lalu ada industri dari pembisnis pangan yang menghidupkan roda perekonomian masyarakat sebagai investasi daerah, kemudian komunitas ataupun petani yang berfokus terhadap pemberdayaan dan pengelolaan ketahan pangan lumbung padi Kabupaten Lingga.

Selanjutnya perguruan tinggi sebagai alat kajian secara akademik terhadap program ketahanan pangan pada lumbung padi dan peran media massa dalam memberikan informasi ke publik tentang ketahanan pangan yang ada di Kabupaten Lingga. Sumber data dan teknik pengumpulan data berupa beberapa data sekunder (Galvan \& Galvan, 2017; Zed, 2014) mengenai lumbung padi di Kabupaten Lingga, 
hal ini yang membahas tentang ketahanan pangan pada lumbung padi yang ada di Kabupaten Lingga pada masa pandemi COVID-19. Selanjutnya hasil deskriptif kualitatif tersebut akan dianalisis oleh penulis secara mendalam atau biasa disebut In Depth Analysis (Tuckman, 1988)

\section{Hasil dan Pembahasan}

\section{Kondisi Ketahanan Pangan Kabupaten Lingga}

Pada saat ini ketahanan pangan pada program lumbung padi di Kabupaten Lingga ditengah pandemi COVID-19 tidak terlepas dari komitmen pemerintah Kabupaten Lingga, pada pertengahan tahun 2020 Kabupaten Lingga mendapatkan 2 unit mesin combine harvester pada tahun 2020 oleh dirjen ketahanan pangan Kementerian Pertanian RI. Hal ini menunjukan bahwasanya komitmen pemerintah pusat ke pemerintah daerah akan keseriusan pengembangan sektor ketahanan pangan pada lumbung padi akan menjadi Kabupaten Lingga sebagai Lumbung Pangan Nasional.

Di bawah naungan Dinas Pertanian Ketahanan Pangan dalam upaya pemenuhan kebutuhan pangan menghadapi akibat pandemi COVID-19 untuk melaksanakan kegiatan pengembangan usaha pertanian yang telah berjalan. Pemerintah daerah Kabupaten Lingga sangat mengaperisiasi atau penghargaan sebesar-besarnya atas capaian hasil program panen lumbung padi, tercatat Kabupaten Lingga pada bulan Maret-April 2021 turut menyumbangkan hasil serentak dari luasan lebih dari 20,00 Ha di Desa Lanjut. Dan saat ini kelompok petani telah panen lagi di sawah bukaan baru di Desa Panggak Darat seluas 0,6 ha (bertahap) dan potensi panen seluas 15.4 ha. Kabupaten Lingga merupakan salah satu tulang punggung pangan di Provinsi Kepri, untuk itu BPTP Balitbangtan Kepri siap terus mendukung dari segi kajian dan pendampingan teknologi demi suksesnya kemandirian pangan di Provinsi Kepulauan Riau.

Meskipun banyak lahan sawah di Kabupaten Lingga yang merupakan sawah bukaan baru dengan tanah miskin hara, $\mathrm{pH}$ relatif masam, Al, dan Fe relatif tinggi dengan bayang-bayang kendala pada fisik, kimia dan biologi tanahnya, hasil panen relatif naik dibandingkan dengan tahun sebelumnya dengan produktivitas 
rata-rata sekitar 3,00-4,50 ton per ha. Di tengah merebaknya Covid-19 dan ancaman keterbatasan bahan pangan di sejumlah daerah, Pemerintah Kabupaten Lingga, Provinsi Kepulauan Riau berbangga hati karena sudah bisa menghasilkan bahan pangan sendiri.

Kabupaten Lingga yang terdiri dari 604 buah pulau besar dan kecil, baru mengenal usaha pertanian. Sebelumnya sejak abad ke-18 hingga Indonesia merdeka, masyarakat Lingga hanya bisa menghasilkan bahan pangan dari sagu. Namun, mayoritas masyarakatnya mengkonsumsi beras sebagai bahan pangan sehari-hari. Sebagaimana diketahui, sejak zaman pemerintahan Kesultanan RiauLingga-Johor-Pahang berkuasa pada abad ke-18 hingga Indonesia merdeka. Pasokan beras Lingga didatangkan dari Singapura dan Malaysia melalui pelabuhan tikus di Batam dan Tanjungpinang. Kini, setelah ratusan tahun menggantukan hidup dari pasokan beras negara tetangga, Kabupaten Lingga sudah bisa menghasilkan bahan pangan sendiri. Bahkan, sudah bisa memasok 32,4 persen kebutuhan beras Lingga per bulan.

\section{Analisis Penta Helix Pembangunan Ketahanan Pangan}

\section{a. Kebijakan Strategis Pemerintah Daerah}

Dinas Pertanian dan ketahanan pangan mempunyai tugas membantu bupati dan wakil bupati dalam melaksanakan urusan pemerintahan di bidang pertanian dan ketahanan pangan. Dalam melaksanakan tugas dinas pertanian dan ketahanan pangan mempunyai tugas menyelenggarakan fungsinya. Kebijakan pemerintah yang dimaksud adalah meningkatkan koordinasi dalam perumusan kebijakan ketahanan pangan. Tercapainya efektifitas koordinasi perumusan kebijakan ketahanan pangan dimana peningkatan koordinasi dan Sinkronisasi sebagai upaya perencanaan pembangunan.

Selanjutnya perlunya kebijakan memperkuat sistem distribusi dan stabilisasi harga pangan pokok program lumbung padi sehingga tingkat produsen dan konsumen dengan cara memperbaiki sistem distribusi pangan dan pemantauan harga ketahanan pangan pada program lumbung padi bisa dilakukan secara berkala. 
Selanjutnya ada pemberdayaan dengan melibatkan masyarakat desa sebagai bentuk penguatan pada Lembaga Distribusi Pangan Masyarakat (LDPM).

Perubahan Renstra Dinas Pertanian dan Ketahanan Pangan Kabupaten Lingga 2016- 2021 adalah panduan pelaksanaan tugas pokok dan fungsi Dinas Pertanian dan Ketahanan Pangan untuk 5 (lima) tahun kedepan, yang disusun berdasarkan hasil evaluasi terhadap pelaksanaan Renstra Dinas Pertanian dan Ketahanan Pangan 2010-2015. Perubahan Renstra ini disusun dengan berpedoman pada Perubahan RPJMD 2016-2021, dan sekaligus dimaksudkan untuk memberikan kontribusi yang signifikan bagi keberhasilan pencapaian sasaran, agenda dan misi pembangunan, serta visi Kabupaten Lingga 2016- 2021, sebagaimana diamanatkan dalam RPJMD Perubahan 2016-2021.

\section{b. Konstribusi Industri Pertanian Lumbung Padi}

Posisi geografis Kabupaten Lingga yang berdekatan dengan Singapura dan Malaysia menjadi daya tarik tersendiri bagi investor asal Taiwan, untuk menanamkan modalnya di bidang pertanian. Telah ada investor asal Taiwan yang berminat membangun pabrik penggilingan padi dan pergudangan modern di Lingga. Selain dua investasi itu, Kementan juga menawarkan sektor pertanian lainnya di Kabupaten Lingga.

Selain itu Kementerian Pertanian menggelontorkan program Upaya Khusus (UPSUS) cetak sawah baru di Kabupaten Lingga seluas 3.000 hektare. Di samping itu, Lingga juga telah ditetapkan sebagai basis pertanian organik untuk memasok kebutuhan pasar Singapura dan Malaysia. Pemerintah daerah merespon dengan baik atas rencana hadirnya investor luar negeri, dimana nantinya pelayanan investasi akan dipermudahkan demi mendapatkan pelayanan yang baik di sektor pertanian. Berdasarkan penejlasan tersebut bahwasanya pemerintah Kabupaten Lingga mengharapkan peran industri atas kemajuan sektor pertanian khususnya program lumbung padi tersebut bisa mendapatkan daya tarik ekonomi bagi masyarakat kabupaten lingga, dimana selama ini pemerintah daerah hanya tergantung pemerintah pusat serta minimnya anggaran yang dilokasi, hal ini dikarenakan Kabupaten Lingga bukan tujuan utama sebagai ketahanan pangan disebabkan bukan wilayah agraria yang memenuhi syarat. 


\section{c. Keterlibatan Kelompok Petani pada Program Lumbung Padi}

Wabah COVID-19 tidak membuat patah semangat para petani di Kabupaten Lingga sehingga usai panen raya, empat Desa di Kabupaten Lingga telah melakukan penyiapan lahan untuk menyambut musim tanam kembali yakni musim tanam kedua 2020 dan di lanjutkan pada tahun 2021.

Kontribusi dalam keberhasilan ketahanan pangan di Kabupaten Lingga adalah optimisnya petani lingga akan keberhasilan program lumbung padi, padahal faktanya Kabupaten Lingga bukan sebuah wilayah pertanian yang bisa di unggulkan, dengan kepercayaan yang optimisme, petani lingga yakin keberhasilan akan program tersebut dengan etikat baik pemimpin daerah dengan meyakinkan para petani untuk membuka lahan pertanian program lumbung padi. Terlebih para kelompok petani diberikan berupa pelatihan oleh Institute Pertanian Bogor pada budidaya padi sawah.

Empat desa yang tengah persiapan musim tanam kedua itu yakni yakni, Desa Lanjut, Desa Sungai Besar, Desa Kerandin dan Desa Bukit Langkap. Hasil panen untuk memenuhi kebutuhan pangan masyarakat khususnya Kabupaten Lingga. Para penyuluh pertanian untuk mengambil langkah-langkah antisipasi dan koordinasi dengan Dinas Pertanian dan Tanaman Pangan untuk tetap memastikan ketersediaan sumber-sumber air bagi pengairan sawah pada keempat desa tersebut. Terpisah, Direktur Jenderal Tanaman Pangan, Kementerian Pertanian (Kementan).

Pengamanan pangan selama pandemi Covid-19 memang menjadi peran sentra. Sesuai arahan Menteri Pertanian Syahrul Yasin Limpo yang meminta dukungan semua sektor pertanian untuk turut mengambil peran tanpa mengabaikan protokol pencegahan penyebaran COVID-19. Dalam upaya mengamankan produksi pangan ini adalah pertarungan dunia akhirat. Sebab barangkali secara kesehatan bisa selesai dengan cepat, kalau semua mengikuti anjuran pemerintah.

Meskipun dalam keadaan berpuasa dan ancaman COVID-19, tidak membuat petani patah semangat untuk menanam padi. Berdasarkan penjelasan tersebut, sesuai dengan arahan pemerintah pusat, artinya para aktor petani akan memiliki semangat baru untuk melakukan terobosan dan mengelola sektor pertanian khususnya program lumbung padi di beberapa kabupaten dan kota baik 
di wilayah peraiaran kepulauan maupun wilayah agraria khususnya di Kabupaten Lingga.

\section{d. Keterlibatan Perguruan Tinggi}

Pada tahun 2020, untuk mewujudkan Lingga sabagai ketahanan pangan nasional, Pemerintah Kabupaten Lingga mendirikan yayasan Politeknik Sultan Mahmud Riayat Syah yang berfokus pada program pendidikan bidang pertanian, perikanan, dan peternakan. Kampus Politeknik Sultan Mahmud Riayat Syah berada di Dabo Singkep. Dalam pendirian yayasan tersebut di hadiri perwakilan anggota DPR RI, Rachmat Gobel

Wakil Ketua DPR RI Rachmat Gobel, melakukan kunjungan kerja (kunker) di Kabupaten Lingga, sekaligus meresmikan Kampus Politeknik Lingga, Kampus ini bernama Politeknik Sultan Sultan Mahmud Riayat Syah (SMRS), yang berlokasi di Kawasan Implasemen Timah di Dabo, Singkep, Kabupaten Lingga. Selain itu, politisi NasDem yang akrab disapa RG ini, juga meresmikan aula Gedung Politeknik dan Perusahaan Air Minum Kemasan BUMD Kabupaten Lingga.

Kampus Politeknik SMRS Lingga saat ini memiliki tiga program studi yakni, perikanan, pertanian, dan peternakan. Selain itu, lokasi kampus itu juga sangat strategis serta gedung perkuliahannya berdekatan dengan gedung bersejarah di Dabo Singkep. Ditambah, satu kompleks dengan industri BUMD Lingga. Kunjungan kerja Wakil Ketua DPRD RI Rachmat Gobel, yang juga Koordinator Bidang Industri dan Pembangunan yang membawahi Komisi IV, V, VI dan Komisi VII DPR RI ini ditemani oleh Bupati dan Wakil Bupati Lingga Nizar-Neko.

Berdasarkan penjelasan diatas bahwasanya pendirian perguruan tinggi sangat pengaruhnya akan sektor ketahanan pangan, tidak dipungkuri jika sebuah wilayah harus memiliki wawasan yang lebih mandiri terhadap pengetahuan sektor ketahanan pangan, artinya pemerintah daerah melalui yayasan yang didirikan nantinya akan lebih berkembang lagi berbagai inovasi ketahanan pangan dan lebih memfokuskan perkembangan ketahanan pangan khusunya program lumbung padi. Hal ini akan memberikan dampak positif kedepannya pada potensi-potensi yang 
bisa di kelola oleh petani untuk memetakan wilayah yang layak untuk menjadikan program lumbung padi secara berkelanjutan.

\section{e. Informasi Publik Oleh Media}

Media massa sebagai wadah pers dan alat komunikasi massa dinilai punya peran penting dalam mewujudkan keterbukaan informasi publik. Dari tahun 2019 hingga saat ini peran media di Kabupaten Lingga menunjukan bahwasanya informasi yang disampaikan ke masayarakat tergolong positif, hal ini dikarenakan konsistennya media dalam mempromosikan Kabupaten Lingga sebagai lumbung padi menjadi nasional di Kepulauan Riau. Meskipun dalam kondisi pandemu COVID-19, informasi serta kondisi tentang ketahanan pangan di Kabupaten Lingga tetap diekspos.

Gambar 1. Publikasi Beberapa Media Nasional dan Lokal pada Program Lumbung Padi di Kabupaten Lingga
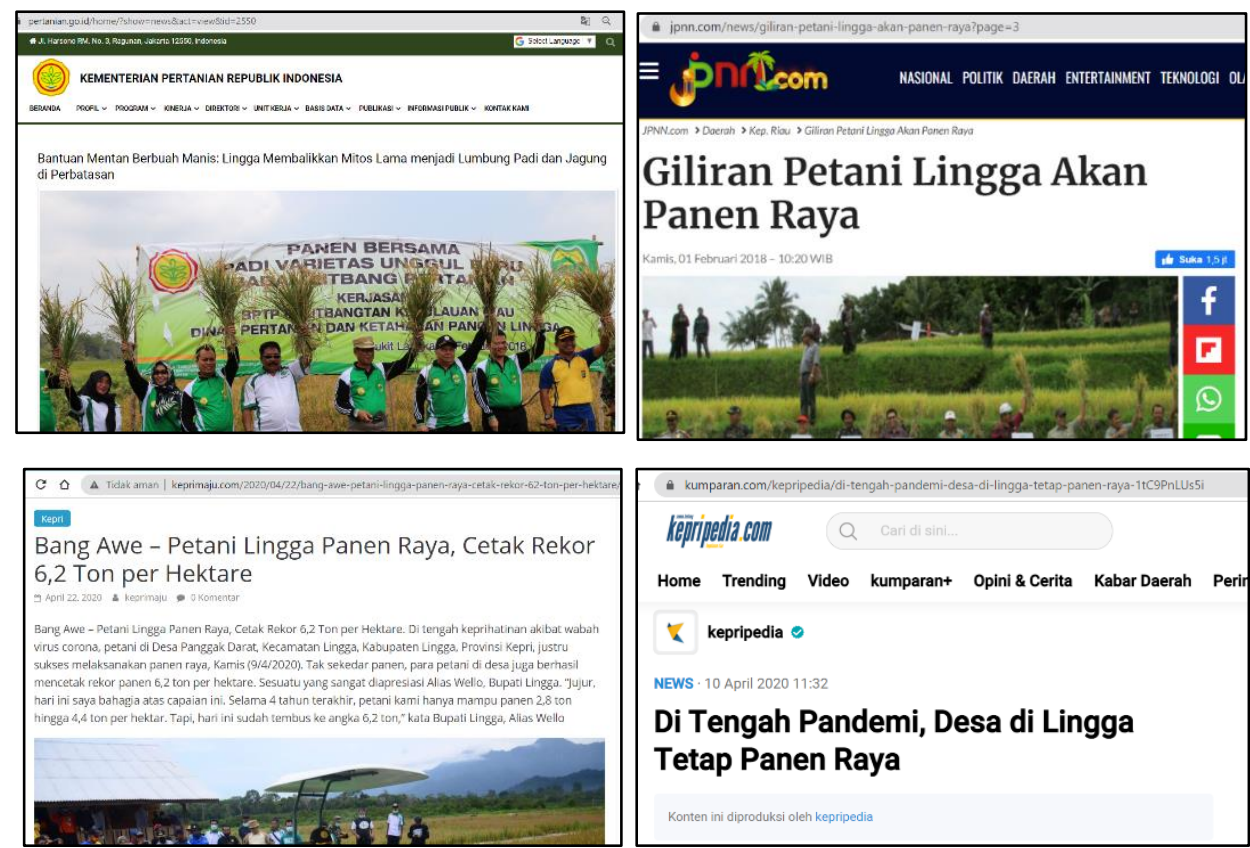

Sumber : Dari berbagai sumber, 2021.

Mulai dari media nasional dan media lokal yang sangat memberikan kontribusi sebagai bentuk agen kontrol agar ketahanan pangan di Kabupaten Lingga bisa di telusuri dengan mudah baik di media online dan media cetak. Meskipun saat ini media massa mempunyai konsisten yang tinggi terhadap ketahanan pangan dalam pemberitaan, media massa yang ada di Kabupaten Lingga harus mengkritisi 
beberapa kebijakan terhadap ketahanan pangan, khususnya terhadap kondisi kesejahteraan masyarakat dan terhindar pemberitaan yang menyudutkan masyarakat di tengah pandemi COVID-19. Media harus bisa melihat kondisi yang wajib memberitakan demi keterbukaan informasi yang ideal.

\section{Kesimpulan}

Pengembangan konsep penta helix pada sektor ketahanan pangan di Kabupaten Lingga khususnya pada program lumbung padi harus mempunyai penguatan secara berkelanjutan apalagi dalam kondisi pandemi COVID-19 yang tidak ada kepastian. Konsep penta helix dengan melibatkan unsur diantaranya pemerintah harus bisa berkomitmen terhadap apa yang telah menjadi kebijakan strategis sebagai upaya mengantisipasi panen raya ataupun krisis pangan karena dominan sektor pertanian khususnya lumbung padi di provinsi Kepulauan Riau berada di Kabupaten Lingga.

Selanjutnya pebisnis industri lumbung padi, pada sisi industri ketahanan pangan di Kabupaten Lingga memiliki rasa bertanggung jawab atas modal usahanya dalam memberikan kontribusi kepada kesejahteraan petani yang berlaku adil, hal ini akan menjadi tolak ukur sejauh mana pendapatan asli daerah yang didapatkan setiap tahunnya di sektor ketahanan pangan di Kabupaten Lingga. Lalu ada keterlibatan komunitas yang berpartisipasi dalam sektor pertanian terus bisa mengawasi aktifitas pertanian agar tidak terjadinya konflik sosial agar program tersebut juga baik dalam pengambilan keputusan maupun sebagai kebutuhan konsumen di sektor ketahanan pangan pada lumbung padi di Kabupaten Lingga.

Keterlibatan perguruan tinggi sangat menjadi penting untuk bahan kajian pemerintah dan swasta agar bisa minimalisir setiap potensi akan bisa mengantisipasi kegagalan kebijakan sektor ketahanan pangan di Kabupaten Lingga. Dan yang terakhir media harus mempunyai kredibilitas yang tinggi dalam mempublikasikan, serta memberikan informasi ke hak layak ramai secara profesional jauh akan kepentingan-kepentingan individu maupun kelompok tertentu agar peran media pemberi informasi bisa tersampaikan secara meluas. 


\section{Referensi}

Adiguna, S., \& Asyiawati, Y. (2019). Upaya pengendalian penggunaan ruang (Studi kasus : kawasan perdesaan Kerandin-Bukit Langkap, Kecamatan Lingga Timur, Kabupaten Lingga, Provinsi Kepulauan Riau). Prosiding Perencanaan Wilayah Dan Kota; Vol 5, No 1, 249-258. http://repository.unisba.ac.id:8080/xmlui/handle/123456789/22134

Amrial, A., Muhammad, A., \& Muhammad, E. (2017). Penta helix model: A sustainable development solution through the industrial sector. Social and Human $\quad$ Sciences, 14(1), 152-156. https://www.researchgate.net/publication/321106743

Bairagi, S., Mishra, A. K., \& Durand-Morat, A. (2020). Climate risk management strategies and food security: Evidence from Cambodian rice farmers. Food Policy, 95. https://doi.org/10.1016/j.foodpol.2020.101935

Blekking, J., Waldman, K., Tuholske, C., \& Evans, T. (2020). Formal/informal employment and urban food security in Sub-Saharan Africa. Applied Geography, 114. https://doi.org/10.1016/j.apgeog.2019.102131

Brück, T., \& d'Errico, M. (2019). Food security and violent conflict: Introduction to the special issue. World Development, 117, 167-171. https://doi.org/10.1016/j.worlddev.2019.01.007

Creswell, J. W. (2014). Qualitative inquiry and research design: Choosing among five approaches. Sage Publication.

Dinda, C. (2020). Pentingnya menjaga ketahanan pangan di masa pandemi COVID-19. Localisesdgs-Indonesia. https://localisesdgsindonesia.org/beranda/v/pentingnya-menjaga-ketahanan-pangan-dimasa-pandemi-covid-19

Doelman, J. C., Stehfest, E., Tabeau, A., \& van Meijl, H. (2019). Making the Paris agreement climate targets consistent with food security objectives. Global Food Security, 23, 93-103. https://doi.org/10.1016/j.gfs.2019.04.003 
Doocy, S., Ververs, M. T., Spiegel, P., \& Beyrer, C. (2019). The food security and nutrition crisis in Venezuela. Social Science and Medicine, 226, 63-68. https://doi.org/10.1016/j.socscimed.2019.02.007

Galvan, J. L., \& Galvan, M. C. (2017). Writing literatur reviews : A guide for student of the social and behavior sciences (7th ed.). Routledge.

Halibas, A. S., Sibayan, R. O., \& Maata, R. L. R. (2017). The penta helix model of innovation in Oman: An HEI perspective. Interdisciplinary Journal of Information, Knowledge, and Management, 12(1), 159-174.

Helton, J. J., Moore, A. R., \& Henrichsen, C. (2018). Food security status of mothers at-risk for child maltreatment. Children and Youth Services Review, 93, 263-269. https://doi.org/10.1016/j.childyouth.2018.07.031

Mahadiansar, M., \& Aspariyana, A. (2020). PEST analysis model dalam pengembangan potensi wisata pulau Benan Kabupaten Lingga Kepulauan Riau. Indonesian Journal of Tourism and Leisure, 1(1), 1425. https://doi.org/10.36256/ijtl.v1i1.93

Moleong, L. J. (2012). Metodelogi penelitian kualitatif. Remaja Rosdakarya.

Nechifor, V., Ramos, M. P., Ferrari, E., Laichena, J., Kihiu, E., Omanyo, D., Musamali, R., \& Kiriga, B. (2021). Food security and welfare changes under COVID-19 in Sub-Saharan Africa: Impacts and responses in Kenya. Global Food Security, 28. https://doi.org/10.1016/j.gfs.2021.100514

Nicholson, C. F., Stephens, E. C., Jones, A. D., Kopainsky, B., Parsons, D., \& Garrett, J. (2021). Food security outcomes in agricultural systems models: Current status and recommended improvements. Agricultural Systems, 188. https://doi.org/10.1016/j.agsy.2020.103028

Pratiwi, K. R. I., Saleh, C., \& Sentanu, I. G. E. P. S. (2019). Policy implementation of tour guides license in maintaining the quality of tourism in bali province. Journal of Indonesian Tourism and Development Studies, 7(3), 175-183. 
Pursyahdad, P. (2018). Analisis kebijakan pemerintah daerah membuka lahan pertanian di Kabupaten Lingga (Studi kasus di Dinas Pertanian dan ketahanan pangan Kabupaten Lingga). Repository UMRAH, 1-30.

Redjeki, E. S. (2020). Building Indonesian food security a review and suggestions. IRJ: Innovation Research Journal, 1(2), 145-149.

Setiawan, R., \& Mahadiansar, M. (2020). Forecasting analysis : The Riau Islands local government role In Covid-19 disaster management. Jurnal Studi Pemerintahan, 11(3). https://doi.org/10.18196/jgp.113121

Shields, C. P., \& Stojetz, W. (2019). Food security and conflict: Empirical challenges and future opportunities for research and policy making on food security and conflict. World Development, 119, 150-164. https://doi.org/10.1016/j.worlddev.2018.07.011

Shuttleworth, M. (2009). Case study research design. Explorable. https://explorable.com/case-study-research-design

Sumarniasih, M. S., \& Antara, M. (2020). Strategy to Maintain the Regional Food Security in Province of Bali, Indonesia. Journal of Experimental Agriculture International, $12-22$. https://doi.org/10.9734/jeai/2020/v42i330480

Tuckman, B. W. (1988). Conducting Educational Research. Harcourt Brace Jovanovich.

Vannozzi Brito, V., \& Borelli, S. (2020). Urban food forestry and its role to increase food security: A Brazilian overview and its potentialities. Urban Forestry and Urban Greening, 56. https://doi.org/10.1016/j.ufug.2020.126835

Walls, H., Baker, P., Chirwa, E., \& Hawkins, B. (2019). Food security, food safety \& healthy nutrition: are they compatible? Global Food Security, 21, 6971. https://doi.org/10.1016/j.gfs.2019.05.005

Yudiatmaja, W. E., Yudithia, Y., Samnuzulsari, T., Suyito, S., \& Edison, E. (2020). Social capital of local communities in the water resources management : an insight from Kepulauan Riau. IOP Conference Series: 
Materials Science and Engineering, 771(1), 012067. https://doi.org/10.1088/1757-899X/771/1/012067

Yudiatmaja, W. E., Kristanti, D., Prastya, I. Y., Yudithia, Y., Samnuzulsari, T., Suyito, S., \& Safitri, D. P. (2021). Social policy on the rural coastal communities: why the implementation fails?. In E3S Web of Conferences (Vol. 232, p. 02006). EDP Sciences.

Yuliawati, Y. (2020). Peluang Sektor Pangan Jadi Andalan Ekonomi Setelah $\begin{array}{llll}\text { Pandemi. } & \text { Katadata.co.id. } & \text { Retrieved }\end{array}$ https://katadata.co.id/yuliawati/berita/5fb4f90fb51bd/peluang-sektorpangan-jadi-andalan-ekonomi-setelah-pandemi

Yunas, N. S. (2019). Implementasi konsep penta helix dalam pengembangan potensi desa melalui model lumbung ekonomi desa di provinsi jawa timur. Matra Pembaharuan; Jurnal Inovasi Kebijakan, 3(1), 37-46. https://doi.org/10.21787/mp.3.1.2019.37-46

Zed, M. (2014). Metode penelitian kepustakaan (3rd ed.). Yayasan Obor Indonesia. 